\title{
Salivary retention after application of fluoride gel using toothbrush or tray: a crossover trial
}

\section{Cecilia Claudia Costa Ribeiro(a) Estevam Carlos de Oliveira Lula(b) Izabelle Maria Cabral de Azevedo(a) \\ Mariana de Figueiredo Lopes e Maia(c) $^{(c)}$ \\ Fernanda Ferreira Lopes ${ }^{(d)}$}

\footnotetext{
(a) Dentistry Postgraduate Program, School of Dentistry, Univ Federal do Maranhão, São Luís, MA, Brazil.

(b) Public Health Postgraduate Program, Univ Federal do Maranhão, São Luís, MA, Brazil.

(c) Health Sciences Postgraduate Program, Univ Federal Maranhão, São Luís, MA, Brazil.

(d) Mother-Child Health Postgraduate Program, Univ Federal Maranhão, São Luís, MA, Brazil.
}

\begin{abstract}
Currently, there are no studies in the literature evaluating salivary fluoride retention after small amounts of fluoride gel are applied to children's teeth. Therefore, the objective of the present study was to compare salivary retention after gel application using a toothbrush or by traditional application with trays. In this crossover study, children with active caries $(n=10)$ were randomized into one of the following treatment groups: a) application of fluoride gel using a tray (control), or b) application of fluoride gel with a toothbrush (treatment). After a 7-day washout period, the treatments were inverted. Unstimulated saliva samples were collected at baseline and 0.5, 5, 15, 30, 60 and 120 minutes after acidulated phosphate fluoride (APF) gel application in order to analyze fluoride retention in saliva. The area under the curve (AUC) was also calculated. There were no differences in fluoride retention after application of small amounts of APF with a toothbrush compared to traditional gel application using trays at all time points studied, and no differences in AUC were observed (Student $t$-test, $p>0.05$ ). These results suggest that application of fluoride gel in children using a toothbrush can be utilized as an option rather than traditional trays, since the same salivary retention of fluoride is obtained using a lower dose.
\end{abstract}

Descriptors: Fluoride; Saliva; Clinical Trial; Cross-Over Studies.

\section{Introduction}

Professionally applied acidulated phosphate fluoride (APF) has been used for dental caries control since the 1970s, and its anticaries effectiveness has been demonstrated. ${ }^{1}$ The application of APF gel has been recommended as part of dental caries treatment in specific risk situations, such as compensation for lack of self-use of fluoride products ${ }^{2-4}$ or individuals with caries experience. ${ }^{5,6}$

Fluoride gel has the best cost-benefit relationship when compared to other types of topical fluorides. ${ }^{7}$ However, adverse effects from fluoride gel have been reported, especially in children. ${ }^{8}$ Depending upon the method of application, 15 to $31 \mathrm{mg}$ of fluoride might be ingested during treatment, resulting in gastrointestinal effects such as nausea, vomiting, and abdominal pain. ${ }^{9,10}$ A lower APF dose can decrease the risk of toxicity and adverse effects, especially in younger children in whom the swallowing reflex is not fully developed. ${ }^{9}$ APF gel is traditionally applied by dispensing 2 to 5 g per tray. ${ }^{11,12}$ The application in adult volunteers of
Submitted: May 02, 2012

Accepted for publication: Aug 15, 2012

Last revision: Aug 30, 2012 
$3.0 \mathrm{~g}$ fluoride gel for 4 minutes in trays, increased the dose of fluoride swallowed about 10-fold compared to brushing with $0.6 \mathrm{~g}$ gel for 2 minutes, although both applications resulted in similar salivary fluoride levels. ${ }^{12}$ Therefore, an alternative to APF use in a tray is to apply fluoride gel with a toothbrush, since this method reduces the amount of gel required, with a consequently reduced risk of toxicity by accidental ingestion. ${ }^{6,12}$

Another alternative for safe gel use in children is to reduce the time of gel application from 4 minutes to 1 minute, since both time periods lead to equally efficient enamel retention and demineralization reduction. ${ }^{13}$ Fluoride levels in whole saliva can be affected by method of delivery, and generally follows the same pattern in plaque samples. ${ }^{14}$ Although salivary retention of fluoride does not necessarily reflect anticaries effect, this data can provide some indication of dose-effective methods of topical fluoride application. ${ }^{15}$

Fluoride levels in saliva are dependent upon the method of application. Previous studies that evaluated salivary kinetics after administration of a lower APF dose were conducted in adult volunteers using different application times when compared to trays. Therefore, the objective of the present study was to compare salivary retention in children after $1 \mathrm{~min}$ ute APF gel application using a toothbrush or by traditional application with trays.

\section{Methodology Study design}

The study was approved by the Ethics Committee of the University Hospital of the Federal University of Maranhão (UFMA) (process \# 33104204/2006). Parents or legal guardians of each child read and signed an informed consent form in which all procedures, possible discomforts or risks, and benefits were fully explained. The study was conducted in the city of São Luís, Maranhão, Brazil, and involved a community whose water supply contained $<0.3$ ppm fluoride.

Based on a pilot study that evaluated fluoride retention after 15 min using 10 caries-active children, and a paired $t$ test, assuming a mean difference of 5.2 and a standard deviation of $6.0,10$ subjects per treatment would be expected to provide $80 \%$ power at a level of significance of $5 \%$. Six-year old children with normal salivary flow $(1.33 \pm 0.45)$ were selected for inclusion. They also had at least three active caries lesions, which were assessed using the Nyvad caries classification system. In this system, score 1 represents active non-cavitated enamel lesions, score 2 represents active cavitated enamel lesions, and score 3 represents active cavitated lesions in dentins. ${ }^{16}$ Exclusion criteria were the presence of deep cavities that could cause pain during the procedures. All caries lesions were evaluated by one examiner (IMCA) by visual/tactile criteria using a dental mirror and dental explorer.

Of the sixty children examined, about seventeen met the inclusion criteria; therefore, using a sequence of random numbers, ten children were randomized into one of the following two treatment groups (five per treatment):

a. application of $2 \mathrm{~mL}$ APF $(1.23 \% \mathrm{~F}$ gel, TopGel, Vigodent S/A, Rio de Janeiro, Brazil) using a tray (Biodinâmica, Ibiporã, Brazil) (control), or

b. application of $0.5 \mathrm{~mL}$ APF with a toothbrush (treatment).

The parents or legal guardians received fluoride toothpaste containing 1100 ppm fluoride (Tandy, Colgate, São Paulo, Brazil) to be used by their children throughout the study. They were also advised that the children should appear on the scheduled day of sample collection after an overnight fast so that each subject would receive breakfast and brush their teeth using about $0.5 \mathrm{~g}$ of fluoride dentifrice followed by the rinsing procedure at one time.

One hour after brushing, an unstimulated saliva sample (baseline) was collected. Next, APF gel was applied for $1 \mathrm{~min}$ as follows:

- in the control group, $2 \mathrm{~mL}$ APF $(25.6 \mathrm{mg}$ fluoride) was applied using disposable trays, and

- in the treatment group $0.5 \mathrm{~mL}$ APF $(6.4 \mathrm{mg}$ fluoride) was applied with a toothbrush for the same period of time, using a disposable syringe to check the volume in both groups.

After a 7 -day washout period, ${ }^{17}$ the treatments were inverted. 


\section{Gel application using trays}

Children received a 1-min application of fluoride gel using trays. They sat with their head slightly tilted forward, and were instructed not to swallow the gel; they could expectorate excess saliva when necessary.

\section{Gel application using a toothbrush}

The children brushed their teeth for 1 min with $0.5 \mathrm{~mL}$ gel, under supervision of a monitor. During treatment, they were instructed not to swallow the gel, and they could expectorate excess saliva when necessary. After treatment application, the children were instructed to expectorate all excess product for $30 \mathrm{~s}$. Unstimulated saliva samples were then collected $0.5,5,15,30,60$, and $120 \mathrm{~min}$ after topical fluoride application for determination of fluoride levels. For this purpose, the children accumulated saliva in their mouths and were asked to expectorate into a plastic container for $60 \mathrm{~s}$. Saliva samples were stored in plastic recipients with an airtight lid, and labeled with the child's identification and time of collection. The children were instructed to not ingest foods or beverages for $120 \mathrm{~min}$ after application. At the end of the study, all children were instructed regarding oral hygiene procedures, and were referred for surgical-restorative treatment at the Pediatric Dentistry Clinic of UFMA.

\section{Salivary fluoride analysis}

Saliva samples were stored in a freezer (Brastemp-Whirlpool Corp., Joinvile, Brazil) at $22^{\circ} \mathrm{C}$ until the time of analysis. For determination of fluoride ion concentration in saliva, the samples were diluted in total ionic strength adjustment buffer (TISAB II, Orion, Thermo Electron Corporation, Beverly, USA) at a ratio of 1:1. Standard fluoride solutions were used to construct the calibration curve. ${ }^{4}$ The quantity of fluoride in saliva was analyzed with a combined fluoride-specific electrode (Orion, Thermo Electron Corporation, Beverly, USA) connected to an ion analyzer (4 Star Orion, Thermo Electron Corporation, Beverly, USA) by one technician who was blinded to the treatment groups. The values were obtained in millivolts $(\mathrm{mV})$ and were converted into ppm using Excel software (Microsoft,
Redmond, USA). The area under the curve (AUC) of salivary fluoride retention for each volunteer was calculated using the ORIGIN 6.0 program (Origin Lab., Northampton, USA).

\section{Statistical analysis}

The data for salivary retention of fluoride at all time points studied and AUC were compared for both APF treatments. After application of the Shapiro-Wilk test, the data showed normal distribution, so the results obtained were compared by the Student $t$-test for paired samples. BioEstat 3.0 software (IDMS, Belém, Brazil) was used for statistical analysis, and the level of significance was set at $p<0.05$.

\section{Results}

All 10 volunteers completed the two phases of the study and no saliva samples were lost. Table 1 shows the mean and standard deviation value of fluoride retention in saliva obtained for the two groups at the different time points studied. Paired analysis revealed no difference in fluoride retention between the group receiving $0.5 \mathrm{~mL}$ APF applied with a toothbrush (treatment group), and the group receiving $2 \mathrm{~mL} \mathrm{APF} \mathrm{using} \mathrm{a} \mathrm{tray} \mathrm{(control} \mathrm{group)} \mathrm{at} \mathrm{any} \mathrm{of}$ the time points studied. There were no differences between groups when AUC was analyzed (Table 1).

\section{Discussion}

Although previous studies have determined sali-

Table 1 - Fluoride retention in saliva (ppm) after application of APF gel with a toothbrush or tray.

\begin{tabular}{c|r|c|c}
\hline \multirow{2}{*}{$\begin{array}{c}\text { Time } \\
(\mathrm{min})\end{array}$} & \multicolumn{3}{|c}{ Treatment groups } \\
\cline { 2 - 4 } & With a tray $(2 \mathrm{ml})$ & With a toothbrush $(0.5 \mathrm{ml})$ & $P$ \\
\hline Baseline & $0.54 \pm 0.13$ & $0.47 \pm 0.13$ & 0.18 \\
\hline 0 & $75.02 \pm 68.24$ & $74.90 \pm 45.12$ & 0.40 \\
\hline 5 & $23.71 \pm 27.61$ & $32.14 \pm 33.53$ & 0.30 \\
\hline 15 & $7.74 \pm 6.53$ & $8.95 \pm 8.37$ & 0.30 \\
\hline 30 & $5.34 \pm 2.49$ & $7.84 \pm 9.60$ & 0.28 \\
\hline 60 & $3.53 \pm 1.90$ & $3.62 \pm 1.61$ & 0.28 \\
\hline 120 & $2.03 \pm 1.19$ & $2.26 \pm 1.50$ & 0.37 \\
\hline AUC & $116.08 \pm 102.78$ & $131.84 \pm 90.24$ & 0.40 \\
\hline
\end{tabular}

Results are reported as mean \pm standard deviation $(n=10)$. 
vary kinetics of fluoride following utilization of small amounts of gel with a toothbrush compared to use of trays, they were conducted in adult volunteers, using a gel application protocol for 2 minutes with a toothbrush ${ }^{12}$ and 4 minutes with a tray. ${ }^{12,15}$ Our results provide comparative analyses on the retention of salivary fluoride in children using a protocol of gel application for 1 minute, which has been studied in Brazil. ${ }^{13}$ Salivary fluoride retention after APF gel application in children's mouths seemed to be more affected by the residual gel remaining in the oral cavity than by the amount applied, since a lower fluoride dose used with a toothbrush resulted in the same salivary retention as traditional application with a tray using a four-fold higher amount of gel.

Only children with active caries lesions were included in the present study. Knowledge about the activity of the disease must be taken into account by the professional when using fluoride gel. ${ }^{18,19}$ Consecutive application of fluoride has been suggested for patients with disease activity in order to increase fluoride reserves. ${ }^{20,21}$ In this respect, the dose of fluoride application able to produce maximum caries reduction with minimal risk or adverse effects needs to be determined. ${ }^{9,10}$ Fluoride application with a toothbrush permits a reduction in the amount of gel that is used compared to trays for four consecutive applications. This approach could be more effective because it saves on cost of trays. In addition, it could be an excellent opportunity to reinforce brushing habits for children during application of APF with a

\section{References}

1. Marinho VC, Higgins JP, Sheiham A. Systematic review of controlled trials on the effectiveness of fluoride gels for the prevention of dental caries in children. J Dent Educ. 2003 Apr;67(4):448-58.

2. Truin GJ, van't Hof MA. Caries prevention by professional fluoride gel application on enamel and dentinal lesions in low caries children. Caries Res. 2005 May-Jun; 39(3):236-40.

3. Ferreira MA, Latorre MR, Rodrigues CS, Lima KC. Effect of regular fluoride gel application on incipient carious lesions. Oral Health Prev Dent. 2005;3(3):141-9.

4. Paes Leme AF, Dalcico R, Tabchoury CP, Del Bel Cury AA, Rosalen PL, Cury JA. In situ effect of frequent sucrose ex- toothbrush. ${ }^{22}$ The fluoride dose used in this experiment on a toothbrush (6.4 mg fluoride) was much lower than a dose that could cause acute toxicity $(5.0 \mathrm{mg} \text { fluoride } / \mathrm{kg})^{23}$ in a child weighing about $20 \mathrm{~kg}$. Therefore, gel application with a toothbrush offers more safety, especially because it has been indicated for public health programs, ${ }^{24}$ such as school programs. ${ }^{25}$ In fact, even preschoolers, a group that demands a high level of care due to fluoride intake risk, can benefit from this method. ${ }^{24}$

Although we were unable to make conclusions about anticaries effect, since the amount of " $\mathrm{CaF}_{2}$ " deposits on the tooth surface ${ }^{26}$ was not evaluated in this study, they can provide an indication that gel application using toothbrush is a dose-effective method, since salivary fluoride retention in children was not affected when a lower dose was used.

\section{Conclusion}

These results suggest that application of fluoride gel with a toothbrush seems to be a dose-effective method, especially when used in public health programs involving children.

\section{Acknowledgements}

The authors thank Ivaldo da Silva Alves Filho, the Chemistry Technician at the Laboratory of Oral Sciences, Federal University of Maranhão, for his valuable contribution. This study received financial support from FAPEMA that supported the English reviewing of this manuscript.

posure on enamel demineralization and on plaque composition after APF application and F dentifrice use. J Dent Res. 2004 Jan;83(1):71-5.

5. Cury JA, Tenuta LMA. Fluoride: its role in dentistry. Bras Oral Res. 2010 Aug;24 Spec Iss 1:9-17.

6. Stokes E, Ashcroft A, Burnside G, Mohindra T, Pine CM. Randomised controlled trial of the efficacy of a high-fluoride gel self-applied by toothbrushing in children at high caries risk. Caries Res. 2011 Sep;45(5):475-85.

7. Brasil. Ministério da Saúde. Secretaria de Atenção à Saúde. Departamento de atenção básica. Guia de recomendações para o uso de fluoretos no Brasil. Brasília (DF): Ministé- 
rio da Saúde; 2009 [citado 21 mar 2012]. Disponível em: http://189.28.128.100/dab/docs/publicacoes/geral/livro_guia_ fluoretos.pdf.

8. Ripa LW. An evaluation of the use of professional (operatorapplied) topical fluorides. J Dent Res. 1990;69(Spec $\mathrm{N}^{\circ}$ ):786-96.

9. Levy, SM: A review of fluoride exposures and ingestion. Community Dent Oral Epidemiol. 1994 Jun;22(3):173-80.

10. Agency for Toxic Substances and Disease Registry. Toxicological profile for fluorine, hydrogen fluoride, and fluorides. Atlanta: U.S. Department of Health and Human Services; 2003 [cited 2012 mar 21]. Available from: http://www.atsdr. cdc.gov/toxprofiles/tp11.pdf.

11. Heath K, Singh V, Logan R, McIntyre J. Analysis of fluoride level retained intraorally or ingested following routine clinical applications of topical fluoride products. Aust Dent J. 2001 Mar;46(1):24-31.

12. Opydo-Szymacze K J, Opydo J. Salivary fluoride concentrations and fluoride ingestion following application of preparations containing high concentration of fluoride. Biol Trace Elem Res. 2010 Nov;137(2):159-67

13. Calvo AF, Tabchoury CP, Del Bel Cury AA, Tenuta LM, da Silva WJ, Cury JA. Effect of acidulated phosphate fluoride gel application time on enamel demineralization of deciduous and permanent teeth. Caries Res. 2012 Jan;46(1):31-7.

14. Zero DT, Raubertas RF, Fu J, Pedersen AM, Hayes AL, Featherstone JD. Fluoride concentrations in plaque, whole saliva, and ductal saliva after application of home-use topical fluorides. J Dent Res. 1992 Nov;71(11):1768-75.

15. Heath K, Singh V, Logan R, McIntyre J. Analysis of fluoride levels retained intraorally or ingested following routine clinical applications of topical fluoride products. Aust Den J. 2001 Mar;46(1):24-31.

16. Nyvad B, Machiulskiene V, Baelum V. Construct and predictive validity of clinical caries diagnostic criteria assessing lesion activity. J Dent Res. 2003 Feb;82(2):117-22.
17. Williams A C, Bower E J, Newton J T. Research in primary dental care. Part 3: designing your study. Br Dent J. 2004 Jun 12;196(11):669-74.

18. American Dental Association Council on Scientific Affairs. Professionally applied topical fluoride: evidence-based clinical recommendations. J Dent Educ. 2007 Mar;71(3):393-402.

19. Adair SM. Evidence-based use of fluoride in contemporary pediatric dental practice. Pediatr Dent. 2006 MarApr;28(2):133-42.

20. Altenburger MJ, Schirrmeister JF, Wrbas KT, Klasser M, Hellwig E. Fluoride uptake and remineralisation of enamel lesions after weekly application of differently concentrated fluoride gels. Caries Res. 2008;42(4):312-8.

21. Jardim JJ, Pagot MA, Maltz M. Artificial enamel dental caries treated with different topical fluoride regimes: an in situ study. J Dent. 2008 Jun;36(6):396-401.

22. Cury J A, Tenuta L M A. How to maintain a cariostatic fluoride concentration in the oral environment. Adv Dent Res. 2008 Jul 1;20(1):13-6. doi: 10.1177/154407370802000104.

23. Tenuta LMA, Cury JA. Limitações do uso de fluoreto em Odontologia: toxicidade aguda e toxicidade crônica (fluorose dental) - Parte III. Jornal ABO. 2009 Jun; 119. http://www.abo.org.br/ jornal/117/artigo1.php.

24. Ministério da Saúde. Guia de recomendações para o uso de fluoretos no Brasil . Brasília (DF): Ministério da Saúde; 2009. $56 \mathrm{p}$.

25. Prefeitura Municipal de Florianópolis. Secretaria Municipal de Saúde. Protocolo de atenção à saúde bucal 2006. [citado 01 jun 2012]. Acessível em: http://www.pmf.sc.gov.br/arquivos/ arquivos/pdf/.

26. Ögaard B. $\mathrm{CaF}(2)$ formation: cariostatic properties and factors of enhancing the effect. Caries Res. 2001;35(Suppl 1):40-4. 